\title{
Minute Locating of Faulting beneath Kobe and the Waveform Inversion of the Source Process during the 1995 Hyogo-ken Nanbu, Japan, Earthquake Using Strong Ground Motion Records
}

\author{
Haruko Sekiguchi, ${ }^{1, *}$ Kojiro Irikura, ${ }^{1}$ Tomotaka Iwata, ${ }^{1}$ \\ Yasumaro Kakehi, ${ }^{2}$ and Mitsuyuki Hoshiba ${ }^{3}$ \\ ${ }^{1}$ Disaster Prevertion Research Institute, Kyoto University, Uji 611, Japan \\ ${ }^{2}$ Japan Meteorological Agency, Chiyoda-ku, Tokyo 100, Japan \\ ${ }^{3}$ Meteorological Research Institute, Tsukuba 305, Japan
}

\begin{abstract}
We estimated the source process of the 1995 Hyogo-ken Nanbu (Kobe), Japan, earthquake based on: 1) locating buried fault planes in the Kobe area by examining particle motion at observation stations in the near-source area and 2) multi-time window linear waveform inversion of strong ground motion seismograms. S-wave particle motion diagrams created theoretically show reverse rotation in the horizontal plane at two stations located on opposite sides of the intersection of the earth's surface and the extension of the buried fault plane. We simulated ground motion at various locations surrounding the buried fault plane and compared their particle motions with observed records to obtain constraints on the location of the fault plane. At least two planes are needed for the rupture area northeast of the epicenter if the causative fault is assumed to be made up of a few perfectly planar structures, and the rupture extended at least $26 \mathrm{~km}$ northeast from the epicenter.

Using a fault model consisting of three planes, two planes on the Kobe side and on the Awaji side, and assuming a step-over at the Akashi strait based on the aftershock distribution, we performed a waveform inversion. The main rupture extended about $45 \mathrm{~km}$ horizontally. Three regions had relatively large moment releases: 1) around the rupture starting point; 2) in the shallow (less than $10 \mathrm{~km}$ ) part of the Nojima fault, which extends along the northwest shore of Awaji Island; and 3) deep (about $10 \mathrm{~km}$ ) under Kobe City. Even though the second subevent on the Nojima fault had a large moment release, it did not generate pulsive waves, because its rise time was long. The two remarkable pulses seen in the seismograms in the Kobe area came from the first and third subevents.
\end{abstract}

\section{Introduction}

The hypocenter of the Hyogo-ken Nanbu (Kobe), Japan earthquake $\left(M_{\mathrm{JMA}}=7.2\right)$, which occurred at 5:46:51.5 a.m. (JST) on January 17, 1995, was under the Akashi strait. The approximate fault rupture during this earthquake was inferred from the aftershock distribution, geodetic displacement and surface breaks on Awaji Island to extend about $50 \mathrm{~km}$ from the northwest shore of Awaji Island to the northeast edge of Kobe City. The surface breaks extended for a distance of about $15 \mathrm{~km}$ along the Nojima fault, but no surface breaks were found in the Kobe area. The aftershocks were distributed along previously mapped active faults (Fig. 1). The aftershock distribution reflects the general location of the causative fault, but it does not accurately map out the fault plane. In addition, there may be errors of about $1 \mathrm{~km}$ in the hypocentral locations. It is therefore difficult to specify the precise location of the fault rupture from the aftershock distribution. The density of the geodetic stations is too low to allow delineation of the fault planes.

We need more details about the causative fault location for the following reasons. In the Kobe area, strong ground motions were recorded at nine

Received July 14, 1995; Accepted March 14, 1996

* To whom correspondence should be addressed. 


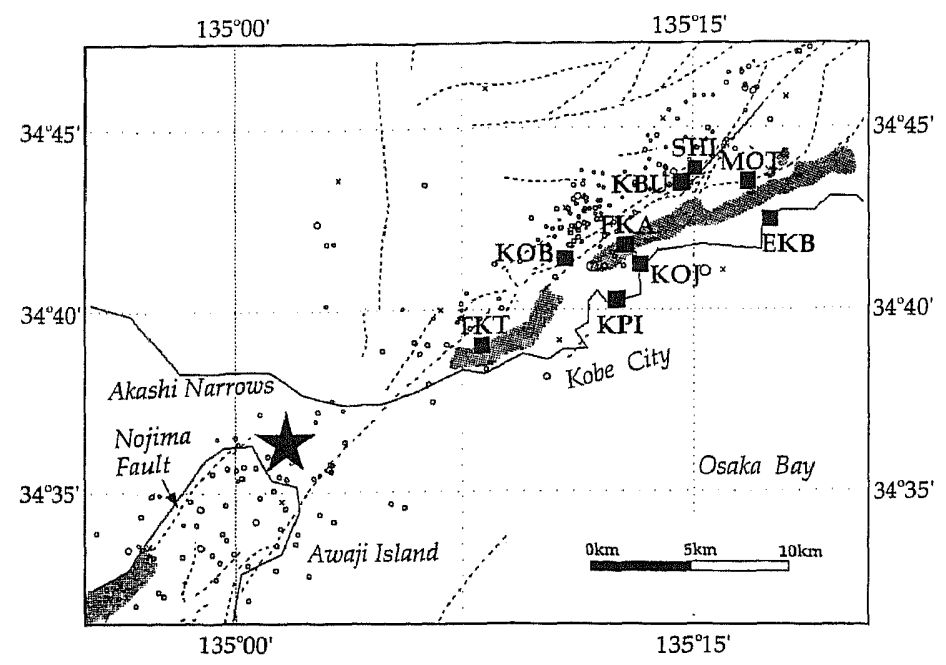

Fig. 1. Aftershock distribution from 1000 to $2400 \mathrm{Jan} .17,1995$ (JST), about 4-18 h after the main șhock. The star indicates the epicenter of the main shock. Broken lines denote active faults. The hatched marks show areas severely damaged at the Japanese seismic intensity of " 7 " (JMA) in which more than $30 \%$ of the wooden structures present were destroyed. Main-shock seismograms were recorded at nine stations in the near-source area.

stations in the near-source region (Figs. 1 and 2). These records are useful for investigating the detailed source process because they were strongly affected by the location of the fault. In other words, for the waveform inversion of the source process, minute locating of a fault model is necessary, especially the relative geometry of the buried fault plane to the observation stations.

We considered that we could estimate the exact fault location by investigating particle motion in the strong ground motion records. The S-wave particle motion diagrams created theoretically show reverse rotation in the horizontal plane at two stations located on opposite sides of the intersection of the earth's surface and the extension of the fault plane (hereafter called the "surface intersection"). This is because the S-wave motion perpendicular to the fault plane is reversed on opposited sides of the surface intersection. Particle motion polarization also changes depending on the relative location of the rupture area. We compared observed and theoretical particle motion to obtain constraints on the location of the fault planes. Using a similar idea, Kikuchi (1995) examined video films recorded in "convenience" stores in the near-source area during the Kobe earthquake. He observed the motions of the objects in those stores and then estimated the relative locations of the stores to the fault trace in comparison with the theoretical ground motion. The theoretical motions he obtained, however, are too simple to fully explain the recorded ground motion seismograms.

Severe damage was done to buildings along a $1 \mathrm{~km}$ wide band running parallel to the fault, but offset $1 \mathrm{~km}$ to the southeast. Some geologists insist that the fault rupture ran just beneath this severely damaged band area, even though there were few aftershocks beneath that area. The reasons for this severely damaged band area are discussed in Sekiguchi et al. (1996).

\section{Data}

We used strong ground motion records obtained from the Committee of Earthquake Observation and Research in the Kansai Area (CEORKA); Japan Meteorological Agency (JMA); Kansai Electric Power Co. Inc.; the Port and Harbor Research Institute; the Research Center of Earthquake Prediction of the Disaster Prevention Research Institute, Kyoto University (RCEP of DPRI); the Research Reactor Institute, Kyoto Univ. (RRI, Kyoto Univ.); the Public Works Research Institute (1995); Osaka Gas; and Kobe City. We also used data from station TKT, which Wald (1996) scanned 

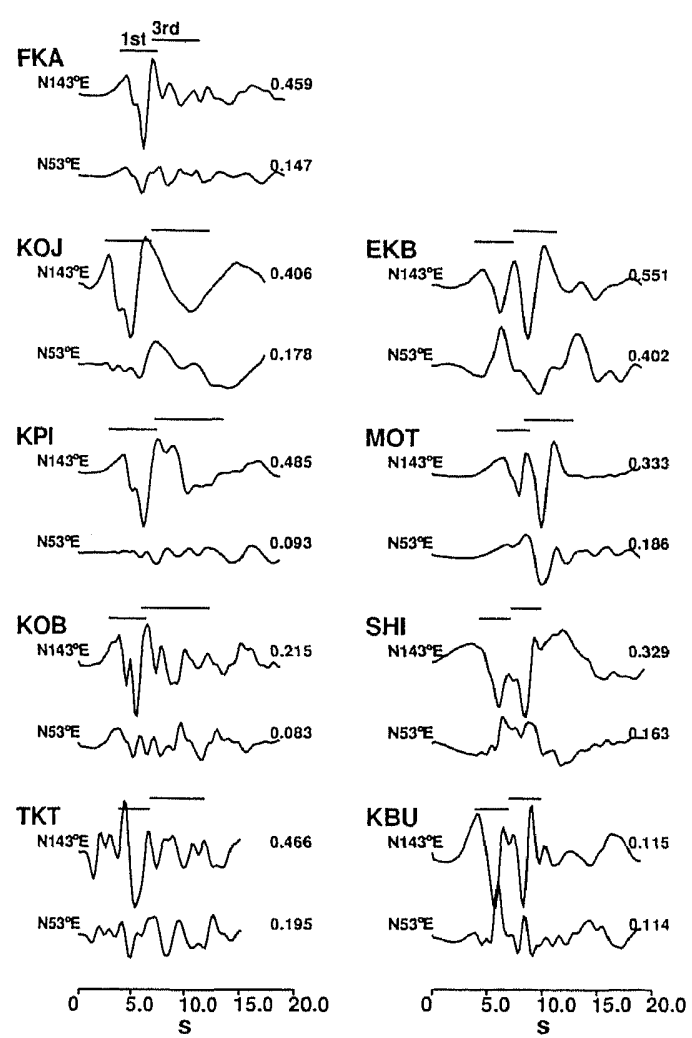

Fig. 2. Observed displacement waveforms measured at the nine stations shown in Fig. 1. Upper traces: the component roughly perpendicular to the surface intersection $\left(\mathrm{N} 143^{\circ} \mathrm{E}\right)$. Lower traces: the component roughly parallel to the surface intersection (N53 $\mathrm{E})$. Maximum absolute amplitude values (unit: $m$ ) are given at the end of each trace. Bars above the waveform portions correspond to the first and third subevents, based on results for the simulated waveforms. The first bars are for the first subevent and the second bars for the third subevent.

and digitized from a report made by the Japan Railway Institute (Nakamura, 1995) (see Table 1 and Figs. 1 and 4). The original seismograms at stations KBU and MOT were clipped in some components. Kagawa et al. (1996) revised those seismograms based on the saturation characteristics of the sensor. Nineteen stations were used in the waveform inversion. Azimuthal coverage of their distribution is fairly good for an epicentral distance greater than $40 \mathrm{~km}$. For the Kobe region, we utilized the mainshock records of nine stations in the near-source area: SHI, KBU, EKB, MOT, FKA, KOB, KPI, KOJ, and TKT. We used these seismograms for the minute locating of the fault in the Kobe area. Note that, of the nine stations, only the seismograms recorded at the SHI, KBU, and KOB stations in the Kobe area were used in the waveform inversion because of difficulty in modeling velocity structure and/or non-linear effect in the data.

\section{Procedure}

Our procedure is as follows: 1) perform preliminary waveform inversion of strong ground motion seismograms with an initial fault model to determine the slip distribution on the fault plane; 2) simulate ground motion from the subevents resulting from step 1);3) compare the observed and theoretical particle motion; and 4) perform final waveform inversion with a revised fault model in which the fault planes are located more precisely. The multitime window linear waveform inversion methodology of Hartzell and Heaton (1983) was applied.

\section{Preliminary Waveform Inversion}

\subsection{Fault model}

We assumed a fault model for the preliminary inversion based on the aftershock distribution during the day of the main shock (RCEP of DPRI). Strike directions and dip angles of the aftershock zones (Fig. 3) differ for two regions (the Kobe side and the Awaji side) separated at the epicenter. Geodetic displacements also indicate a step-over of the fault at the same place (Hashimoto et al., 1996). We utilized a fault model with two fault planes: the Awaji (southwest) plane is $19.5 \mathrm{~km}$ long, strikes $45^{\circ}$, and dips $82^{\circ}$ towards the southeast, and the Kobe (northeast) plane is $37.5 \mathrm{~km}$ long, strikes $53^{\circ}$, and dips $90^{\circ}$. Both faults extend from a depth of about $2.6 \mathrm{~km}$ to about $20 \mathrm{~km}$.

\subsection{Seismic wave velocity structure model}

We estimated the seismic wave velocity structures by forward modeling for Green's functions, which represent the path effects, assuming one-dimensional horizontally layered structures. For the stations around Osaka Bay, we started from the models of Kagawa et al. (1993) and Pitarka and Irikura (1995). By comparing the observed waveforms with synthetic waveforms for the main shock and some aftershocks, we changed the velocity model by trial- 
Table 1. Observed seismograms used in this analysis.

\begin{tabular}{lcccl}
\hline Station & Lat. & Lon. & I/P & Owner \\
\hline ABD & 35.209 & 135.851 & I & Shiga Pref. \\
CHY & 34.439 & 135.659 & I & CEORKA \\
KBU & 34.725 & 135.240 & I,P & CEORKA \\
MOT & 34.725 & 135.281 & P & CEORKA \\
KMT & 34.383 & 135.350 & I & RRI, Kyoto Univ. \\
KOJ & 34.689 & 135.217 & P & Port and Harbor Research Institute \\
AM3 & 34.690 & 135.391 & I & Kansai Electric Power Co. Inc. \\
SHI & 34.731 & 135.250 & I,P & Kansai Electric Power Co. Inc. \\
KPI & 34.670 & 135.208 & P & Kobe City \\
FKA & 34.695 & 135.211 & P & Osaka Gas \\
EKB & 34.710 & 135.290 & P & Public Works Research Institute \\
TKT & 34.649 & 135.138 & P & JR Inst.(scanned and digitized \\
& & & & by Wald, 1996) \\
AID & 34.940 & 134.168 & I & JMA \\
AIO & 33.792 & 134.452 & I & JMA \\
AWA & 34.336 & 134.908 & I & JMA \\
HEG & 34.653 & 135.685 & I & JMA \\
KOB & 34.690 & 135.180 & I,P & JMA \\
KOY & 34.218 & 135.593 & I & JMA \\
MRT & 33.248 & 134.180 & I & JMA \\
MTS & 35.455 & 133.072 & I & JMA \\
OKA & 34.658 & 133.918 & I & JMA \\
OSA & 34.678 & 135.522 & I & JMA \\
SHJ & 33.448 & 135.763 & I & JMA \\
TAG & 35.187 & 136.322 & I & JMA \\
WAC & 35.283 & 135.402 & I & JMA \\
& & & & \\
\hline
\end{tabular}

In column four "I" denotes data used in the waveform inversion, and "P" denotes data used in the investigation of the particle motion diagrams.

and-error to explain the travel time for the main shock and specific phases in the aftershocks. This was done because the origin time and hypocenter of the main shock are expected to be determined more precisely than those of the aftershocks since the main shock was recorded at more stations than the aftershocks and, in contrast, the path effect (i.e., reflected and converted waves) is clear in the aftershock waveform. We obtained different structure models for each station. Examples are shown in Table 2. The discrete wavenumber method (Bouchon, 1981) associated with the reflection transmission matrix method (Kennett and Kerry, 1979) was used to calculate Green's functions.

\subsection{Parameterization}

Faulting is represented as moment release vectors on a planar surface. We put point source grids on the two planes (described above) at $3.0 \mathrm{~km}$ intervals in the strike direction and at $3.2 \mathrm{~km}$ intervals in the dip direction. The slip time history is modeled using eight time windows, each $0.5 \mathrm{~s}$ apart. The displacement in each is represented by a smoothed ramp function with an $0.8 \mathrm{~s}$ rise time. The time windows therefore partially overlap. We set the rupture velocity at $3.1 \mathrm{~km} / \mathrm{s}$ for the first time window.

\subsection{Inversion method}

A constrained, damped, linear, least-squares inversion procedure (Hartzell and Heaton, 1983) was used to obtain the amount of moment release at each grid point and in each time window, which minimized the difference between the observed and synthetic seismograms. We constrained the variation of the rake angle to $180 \pm 70^{\circ}$. Damping was done by minimizing the difference in the total amount of moment release between adjacent grids. All the observed data were band-pass filtered from 0.1 to $1.0 \mathrm{~Hz}$. The Green's functions were also band-pass 


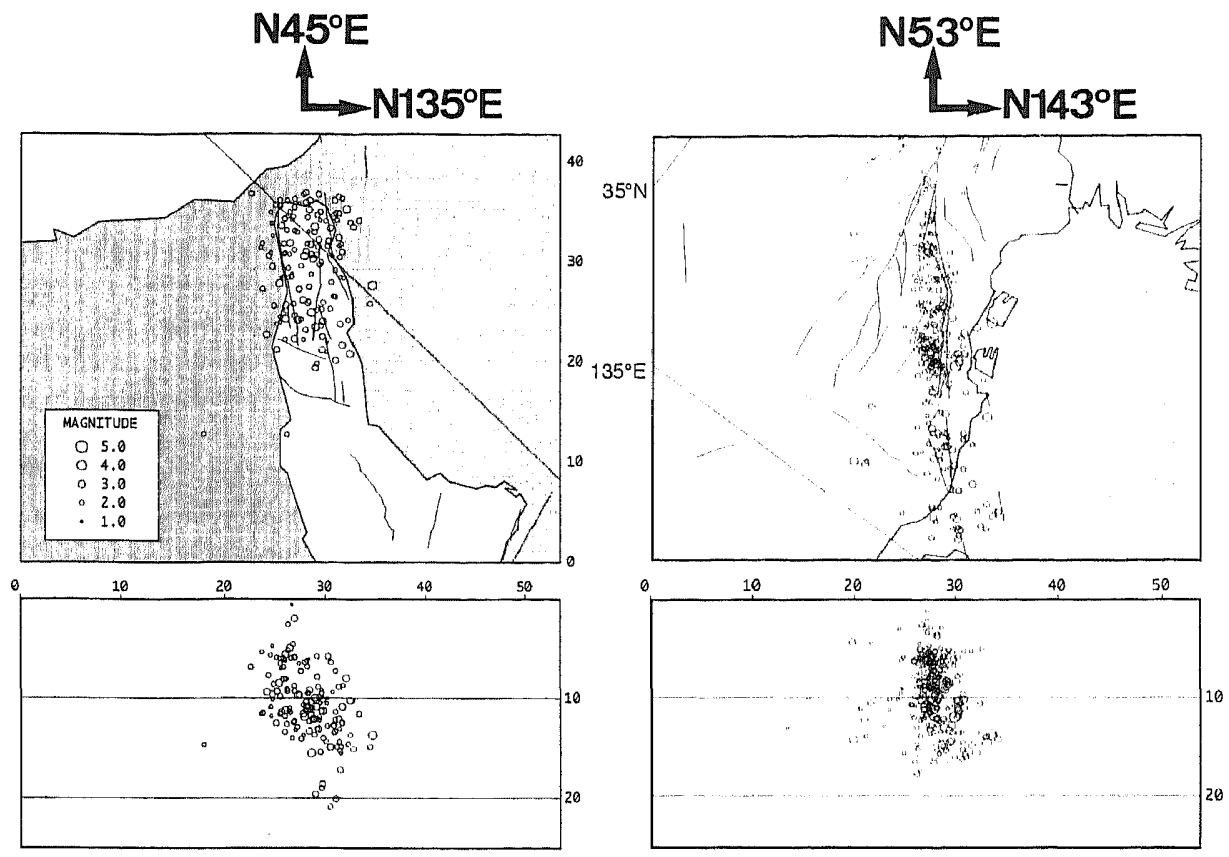

Fig. 3. Aftershock distribution in the same period rotated $45^{\prime \prime}$ for the Awaji side (left) and $53^{\prime \prime}$ for the Kobe side (right).

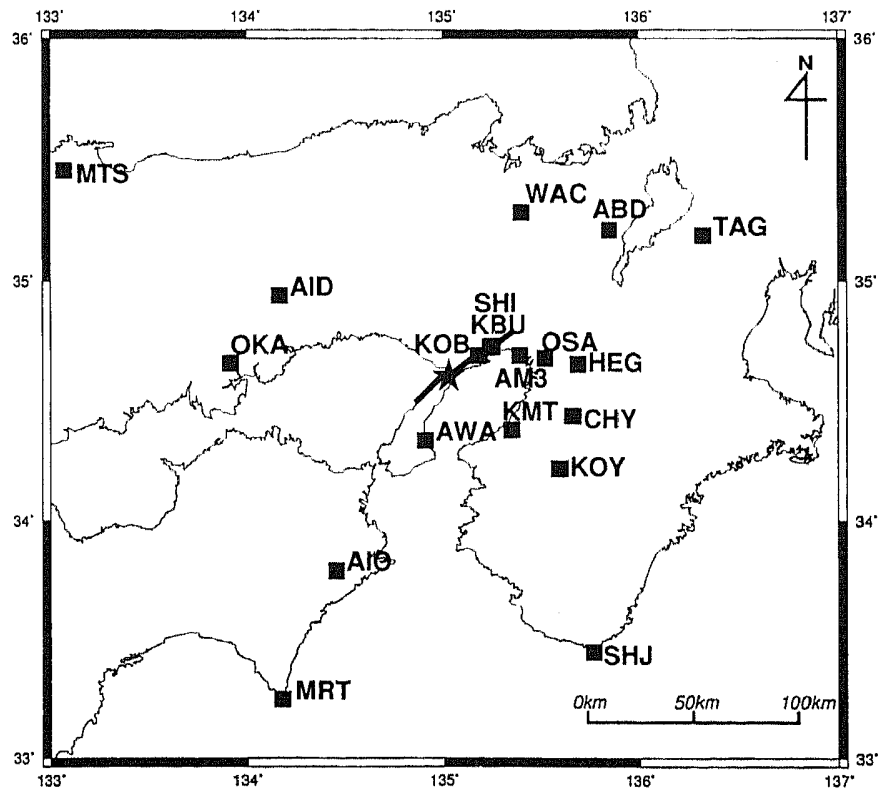

Fig. 4. The 19 observation stations used in the waveform inversion. 
Table 2. Seismic wave velocity structure models of the crust.

\begin{tabular}{|c|c|c|c|c|c|}
\hline Station & $\begin{array}{l}\text { Depth } \\
(\mathrm{km})\end{array}$ & $\begin{array}{c}V_{\mathrm{P}} \\
(\mathrm{km} / \mathrm{s})\end{array}$ & $\begin{array}{c}V_{\mathrm{s}} \\
(\mathrm{km} / \mathrm{s})\end{array}$ & $\begin{array}{l}\text { Density } \\
\left(\mathrm{g} / \mathrm{cm}^{3}\right)\end{array}$ & Condition \\
\hline \multirow[t]{7}{*}{ AM3 } & $0.00-0.23$ & 1.60 & 0.35 & 1.70 & \multirow[t]{7}{*}{ Sediment } \\
\hline & $0.23-0.55$ & 1.80 & 0.55 & 1.80 & \\
\hline & $0.55-1.60$ & 2.50 & 1.00 & 2.10 & \\
\hline & $1.60-5.07$ & 5.50 & 3.20 & 2.60 & \\
\hline & $5.07-18.00$ & 6.00 & 3.46 & 2.70 & \\
\hline & $18.00-34.80$ & 6.70 & 3.87 & 2.80 & \\
\hline & 34.80 & 7.50 & 4.33 & 3.00 & \\
\hline \multirow[t]{6}{*}{$\mathrm{KBU}$} & $0.00-0.40$ & 3.20 & 1.80 & 2.10 & \multirow[t]{6}{*}{ Rock (weathered) } \\
\hline & $0.40-0.55$ & 5.15 & 2.85 & 2.50 & \\
\hline & $0.55-5.00$ & 5.50 & 3.20 & 2.60 & \\
\hline & $5.00-18.00$ & 6.00 & 3.46 & 2.70 & \\
\hline & $18.00-34.50$ & 6.70 & 3.87 & 2.80 & \\
\hline & 34.50 & 7.50 & 4.33 & 3.00 & \\
\hline \multirow[t]{4}{*}{ KOY } & $0.00-4.00$ & 5.50 & 3.20 & 2.60 & \multirow[t]{4}{*}{ Rock } \\
\hline & $4.00-17.80$ & 6.00 & 3.46 & 2.70 & \\
\hline & $17.80-33.00$ & 6.70 & 3.87 & 2.80 & \\
\hline & 33.00 & 7.50 & 4.33 & 3.00 & \\
\hline
\end{tabular}

Three examples: on sedimentary layer, on a weathered rock, and on hard rock.

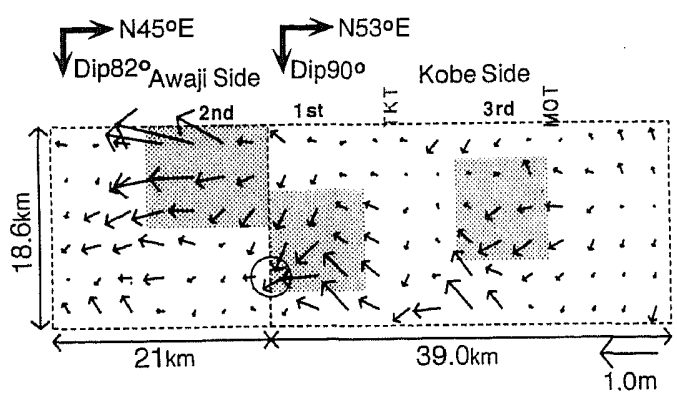

Fig. 5. Total slip vector distribution obtained from the preliminary waveform inversion. Arrows show the movement of the southeast side of the fault against the northwest side. The circle represents the hypocenter. The three hatched areas represent the simplified subevents for theoretical calculation.

filtered in the same range.

\subsection{Results of the preliminary inversion}

Three separate regions with relatively large moment releases were obtained (Fig. 5): 1) a first subevent around the rupture starting point, 2) a second subevent in the shallow (less than $10 \mathrm{~km}$ depth) part of the Nojima fault, and 3) a third subevent deep (about $10 \mathrm{~km}$ ) under Kobe City. The second subevent had a relatively long rise time. An examination of the contribution of the model fault to the synthesized waveforms revealed that the main source contribution to the first and second large pulses measured at KBU and SHI (Fig. 2) came from the first and third subevents, respectively. The waveform portions from the two subevents are indicated by bars over the seismograms in Fig. 2 . There was a large and a short pulse from the first subevent measured, at all the stations. In contrast, large pulses from the third subevent are present only at KBU, SHI, MOT, and EKB. The pulses from the second subevent on the Awaji side of the fault are estimated to have overlapped with the pulses from the third subevent at the five stations to the sourtheast. But the pulses from the second subevent were of low frequency, and it is possible to neglect any contribution to the second large pulse (mainly from the third subevent) in the records in the Kobe area.

\section{Simulation of Ground Motion from Specific Subevents}

On the basis of the above results, we assumed a 
simplified source process model consisting of three subevents (Fig. 5). Each subevent has a finite source area with a uniform right-lateral strike slip and circular rupture propagation at a constant speed from the hypocenter. We simulated the ground motion at stations on both sides of the Kobe side of the fault. Eight stations surround the simplified third subevent (Fig. 10). The velocity structure models are the same for all the stations. We calculated the theoretical ground motion for each subevent separately. We shifted the third simplified subevent area so that it was shallower than the area with large moment release so that the relative amplitude of the pulse from the simplified third subevent would be in agreement with the pulse from the first simplified subevent. This suggests the possibility that the third subevent was located shallower than estimated by the waveform inversion of strong ground motion records, mainly at a distance of several tens of kilometers. The rotation direction of the theoretical particle motion is the same for
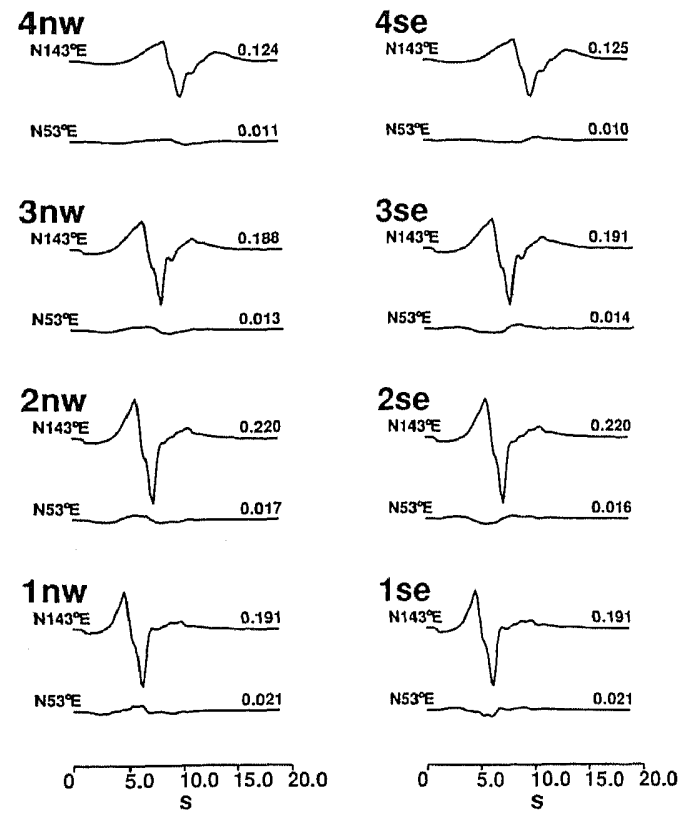

Fig. 6. Theoretical waveforms for the first subevent at eight stations shown in Fig. 7. Upper traces: the component perpendicular to the surface intersection $\left(\mathrm{N} 143^{\circ} \mathrm{E}\right)$. Lower traces: the component parallel to the surface intersection (N53 ${ }^{\circ} \mathrm{E}$ ). The relative maximum amplitude values are given at the end of each trace. both cases, which shows the robustness of this method.

\section{Comparison of Observed and Theoretical Particle Motions}

\subsection{The first subevent}

The theoretical waveforms are shown in Fig. 6, and particle motion from the simplified first subevent is shown in Fig. 7. Particle motion is clockwise at stations on the southeast side of the surface intersection, and counterclockwise on the northwest side. The component perpendicular to the surface intersection (hereafter called "perpendicular motion") is dominant.

Let us compare this with the observed records. The observed particle motion from the first subevent, indicated by the first bars in Fig. 2, are shown in

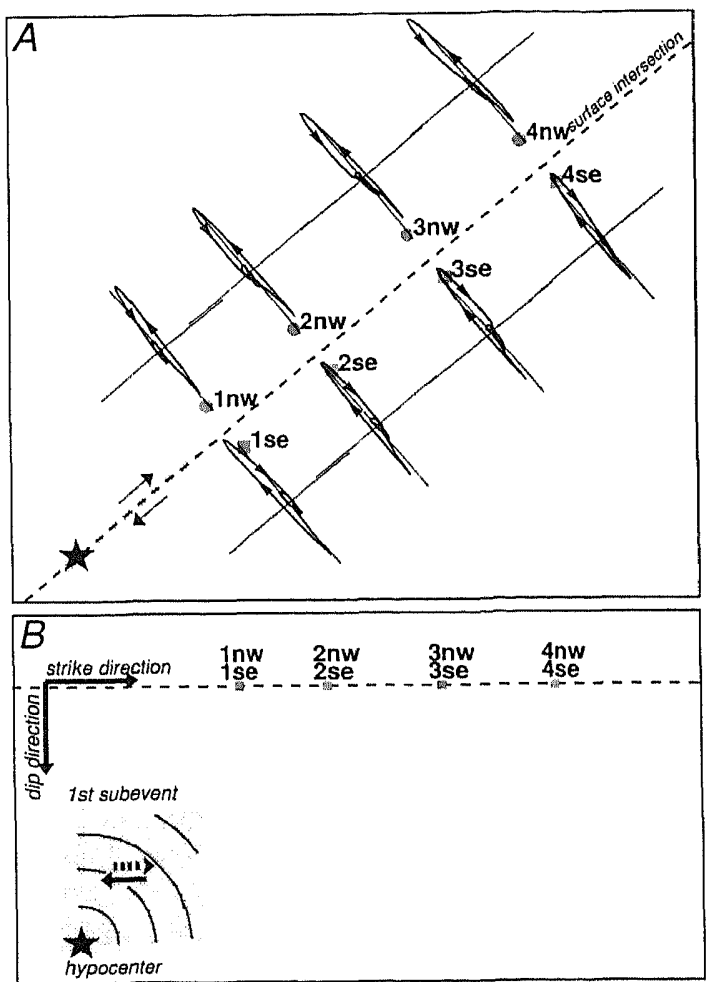

Fig. 7. Theoretical particle motion diagrams on the horizontal plane from the first subevent. Each diagram is normalized by its maximum amplitude value. At stations indicated by a rectangle, particle motion was clockwise and at stations indicated by a circle, particle motion was counterclockwise. 


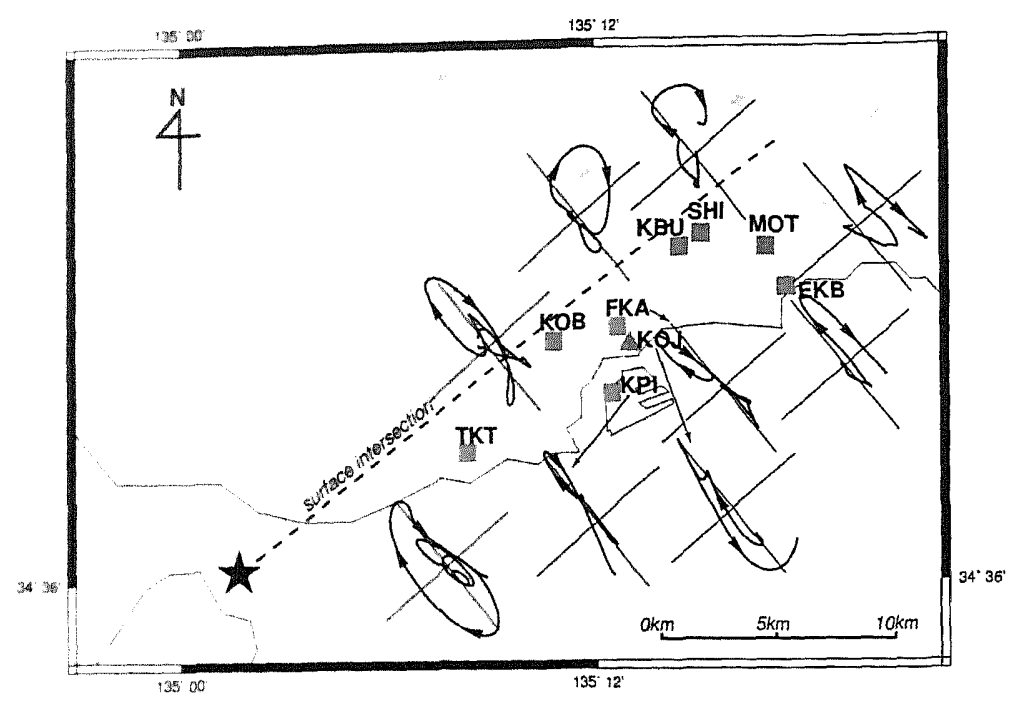

Fig. 8. Observed particle motion from the first subevent. Each diagram is normalized by its maximum amplitude value. At stations indicated by a rectangle, particle motion was clockwise and at the station indicated by a triangle, the rotation of particle motion could not be clearly determined. Arrows show the horizontal component of static displacements (Hashimoto et al., 1996).

Fig. 8. For the first subevent, the particle motion diagrams are drawn from the P-onset. Except for $\mathrm{KOJ}$. particle motion at all of the stations rotated clockwise, indicative that all the stations were on the southeast side of the surface intersection.

\subsection{The third subevent}

Next, let us investigate particle motion from the third subevent. The theoretical waveforms are shown in Fig. 9, and particle motion is shown in Fig. 10. In the area ahead of the stopping position of the subevent (4se and $4 \mathrm{nw})$, the waveforms have a shortened, large amplitude in the perpendicular component because of the directivity effect. Particle motion rotated clockwise on the southeast side of surface intersection (4se) and counterclockwise on the northwest side ( $4 \mathrm{nw}$ ). This is the same rotation direction found for the first subevent in the theoretical calculation. In contrast, on the side 12 se, $2 n w, 3 s e$ and $3 n w$ ) and in the rear (1se and $1 n w$ ) of the rupture area, particle motion was clockwise on the northwest side of the surface intersection and counterclockwise on the southeast side. This rotation direction is the reverse of that at the stations ahead of the subevent stopping position (compare 1se, $2 \mathrm{se}$, and $3 \mathrm{se}$ with $4 \mathrm{se}$ ). Just to the side of the rupture area (2se, $2 \mathrm{nw}, 3 \mathrm{se}$, and $3 \mathrm{nw}$ ), the amplitude of the perpendicular motion is about three times that of the parallel motion.

In the observed waveforms, motion from the third subevent is seen as an isolated pulse at northeastern stations KBU, SHI, MOT, and EKB (Fig. 2). Particle motion at these four stations is of two types: at $\mathrm{KBU}$ and SHI the rotation was clockwise, and at MOT and EKB rotation was counterclockwise (Fig. 11). We infer that KBU and SHI correspond to "3nw," and MOT and EKB to "3se". At southwestern stations TKT, KOB, KPI, KOJ, and FKA, there was no large amplitude pulse from the third subevent. This is consistent with the theoretical prediction that the waves were elongated, as seen at stations 1se, 1nw, 2se, and 2nw in Fig. 9. At KOB, particle motion was clockwise, whereas at FKA and TKT, it was counterclockwise. The amplitude of the parallel motion was comparable to that of the perpendicular motion at these three stations. These findings suggest that $\mathrm{KOB}$ corresponds to $2 \mathrm{nw}, \mathrm{FKA}$ to 2 se, and TKT to 1 se. We could not determine on which side of the surface intersection KPI and KOJ were located. This may be because, at KPI and KOJ, motion from the third subevent was affected by non-linear effects in soft soil deposits (Aguirre and Irikura, 1995; Kawase, 1995). 

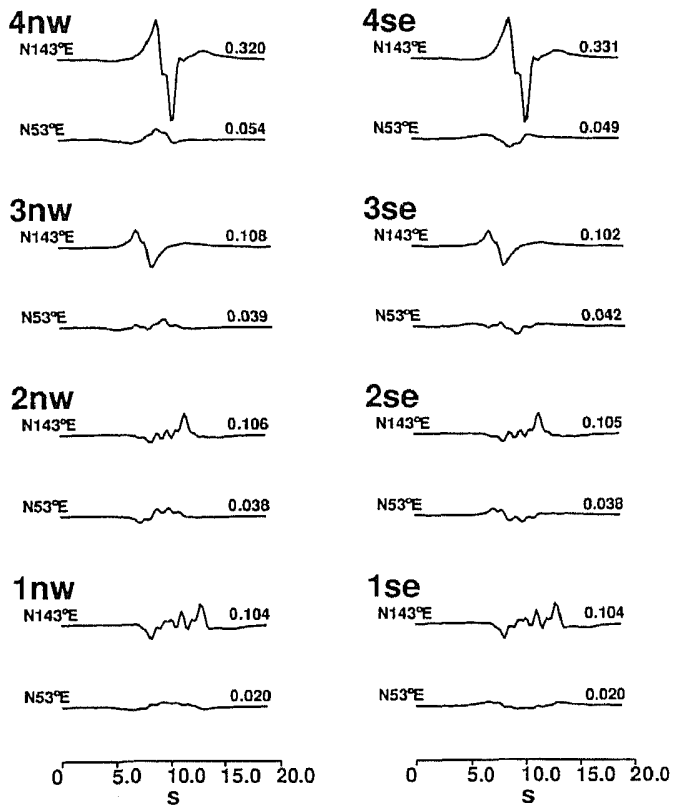

Fig. 9. Theoretical waveforms from the third subevent. Upper traces: the component perpendicular to the surface intersection $\left(\mathrm{N} 143^{\circ} \mathrm{E}\right)$. Lower traces: the component parallel to the surface intersection $\left(\mathrm{N} 53^{\circ} \mathrm{E}\right)$. The relative maximum amplitude values are given at the end of each trace.

\subsection{Summary of the particle motion investigation}

In summation: 1) the surface intersection of the first subevent plane was located northwest of all nine stations, whereas 2) that of the third subevent plane was located southeast of KOB, KBU, and SHI, and northwest of TKT, FKA, MOT, and EKB. The third subevent rupture area extended at least beyond MOT, about $26 \mathrm{~km}$ from the epicenter. These intersection lines are consistent with known active fault lines and agree with the geodetic data. The arrows in Figs. 8 and 11 show the horizontal components of the static displacements caused by this earthquake. If we assume that the causative fault is made up of a few perfect planar structures, at least two planes are needed for the Kobe side of the rupture.

\section{Final Inversion}

\subsection{Fault model}

On the basis of the requirements obtained in the particle motion investigation (i.e. location of the

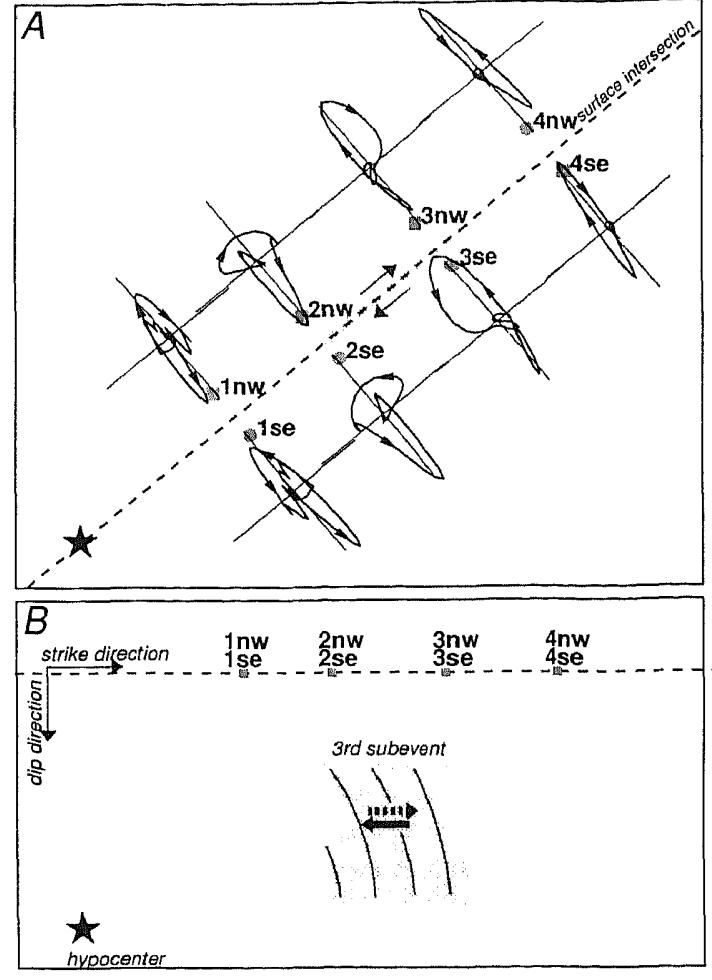

Fig. 10. Theoretical particle motion diagrams from the third subevent. Each diagram is normalized by its maximum amplitude value. At stations indicated by a rectangle, particle motion was clockwise and at stations indicated by a circle, particle motion was counterclockwise.

surface intersection of the fault plane), we revised the fault model. Taking into account the location of the surface breaks on Awaji Island and the aftershock distribution (straightness of strike and almost vertical dip angle northeast of the epicenter), we assumed three planes: plane "A" is $21.0 \mathrm{~km}$ long, strikes $45^{\circ}$, and dips $82^{\circ}$ towards the southeast; plane " $B$ " is $15.0 \mathrm{~km}$ long, strikes $53^{\circ}$, and dips $90^{\circ}$; and plane " $\mathrm{C}$ " is $24.0 \mathrm{~km}$ long, strikes $233^{\circ}$, and dips $85^{\circ}$ towards the northwest (shown schematically in Fig. 12). All of the faults extend from the surface to a depth of about $20 \mathrm{~km}$. We put the junction between planes $B$ and $C$ near the area where the density of the aftershock epicenters changes. The parameters for these planes are shown in Table 3. Because in the preliminary inversion, we obtained large moment releases at the shallowest

Vol. 44, No. 5, 1996 


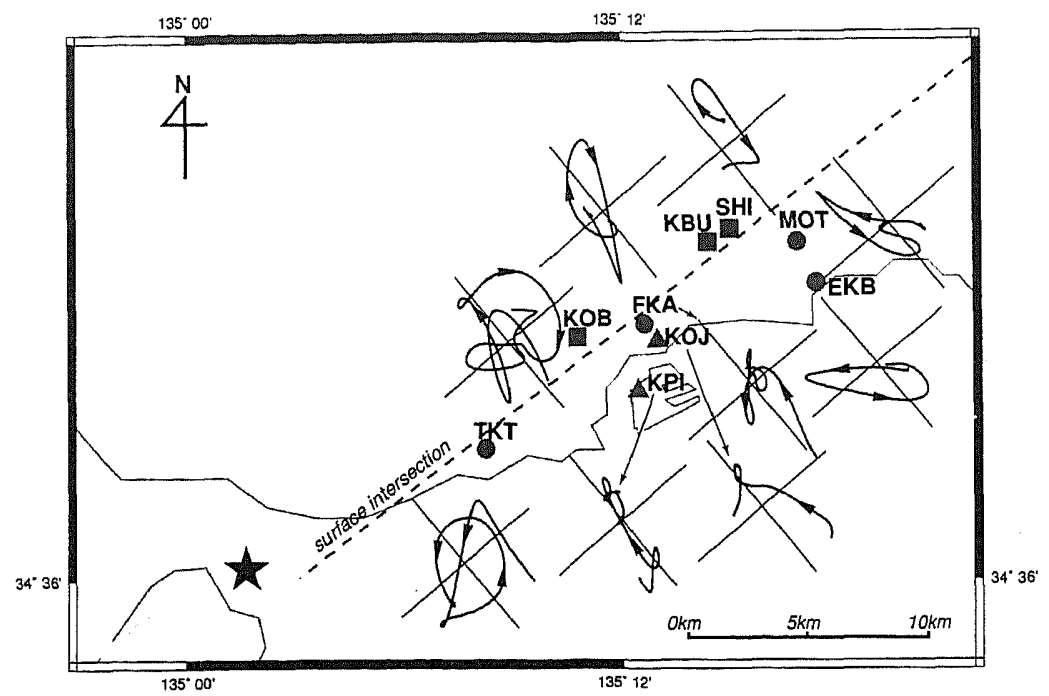

Fig. 11. Observed particle motions from the first subevent. Each diagram is normalized by its maximum amplitude value. At stations indicated by a rectangle, particle motion was clockwise and at stations indicated by a circle, particle motion was counterclockwise. At stations indicated by a triangle, the rotation of particle motion could not be clearly determined. Arrows show the horizontal component of static displacements (Hashimoto et al., 1996).

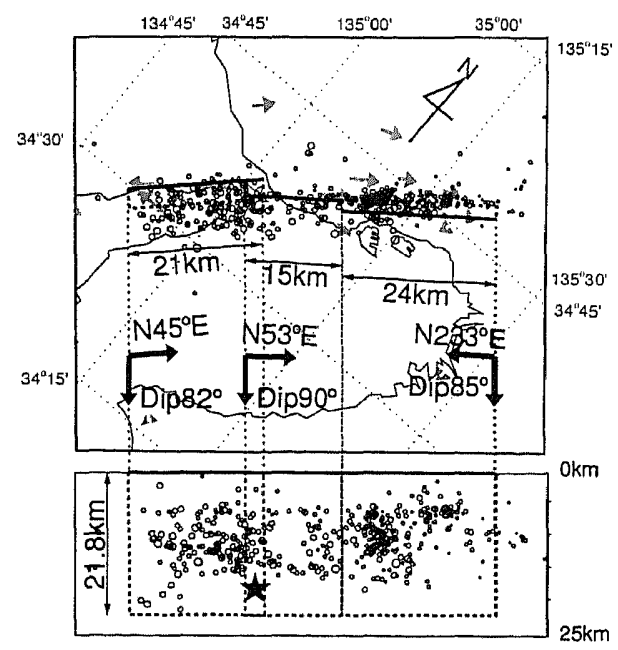

Fig. 12. Revised fault model on the aftershock distribution for the same period as in Figs. 1 and 3. Gray arrows show the horizontal component of static displacements (Hashimoto et al., 1995).
Table 3. Parameters of the fault model for the final inversion.

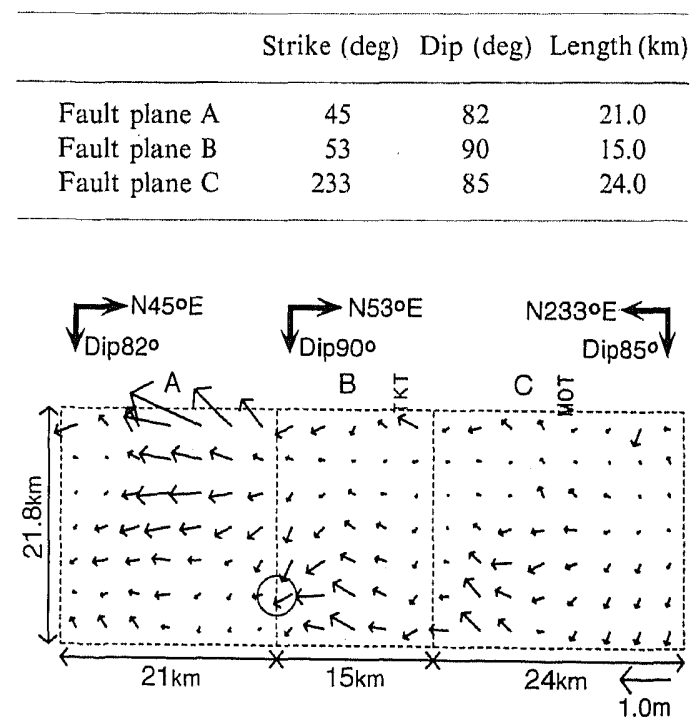

Fig. 13. Total slip vector distribution for the revised fault model. Arrows show the movement of the southeast side of the fault against the northwest side. The circle represents the hypocenter. 


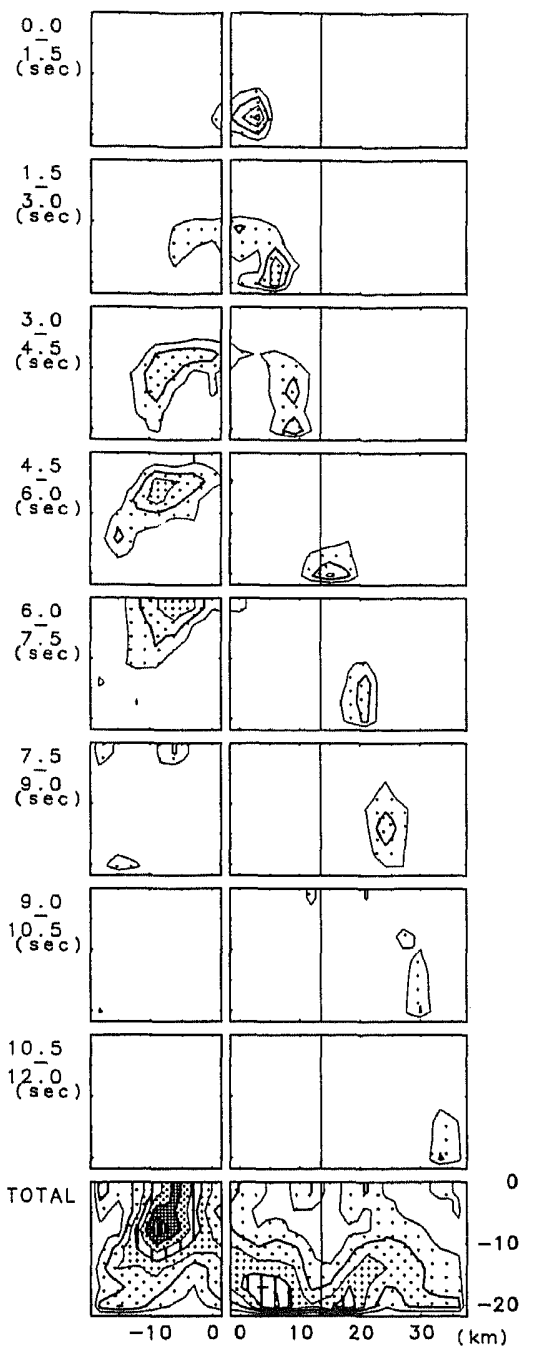

A grids on the Awaji side, we extended the fault plane model to the earth's surface (shallowest grids at the depth of about $1.0 \mathrm{~km}$ ). The source time function, number of time windows, interval of the time windows, rupture velocity, and constraint for variation of rake angles were the same as in the preliminary inversion.

\subsection{Results and discussion}

The total slip vector distribution is shown in Fig. 13. The time progression of rupture in terms of moment release is shown in Fig. 14. A summary of the slip parameters is given in Table 4. The obtained moment release functions at each grid point are shown in Fig. 15. A comparison of the observed waveforms with synthetic waveforms is shown in Fig. 16. General features of the source

Table 4. Slip parameters.

\begin{tabular}{lcc} 
& \multicolumn{2}{c}{ Slip parameters } \\
\cline { 2 - 3 } & Maximum slip $(\mathrm{m})$ & $M_{\mathrm{o}}\left(\times 10^{17} \mathrm{Nm}\right)$ \\
\hline Fault plane A & 1.55 & 85.9 \\
Fault plane B & 0.55 & 48.8 \\
Fault plane C & 0.48 & 56.6 \\
Total & 1.55 & 191.2
\end{tabular}

Fig. 14. Time progression of rupture (moment release) and distribution of the total moment release. Each time window is $1.5 \mathrm{~s}$. The area shown is the same as the fault model shown in Figs. 12 and 13.

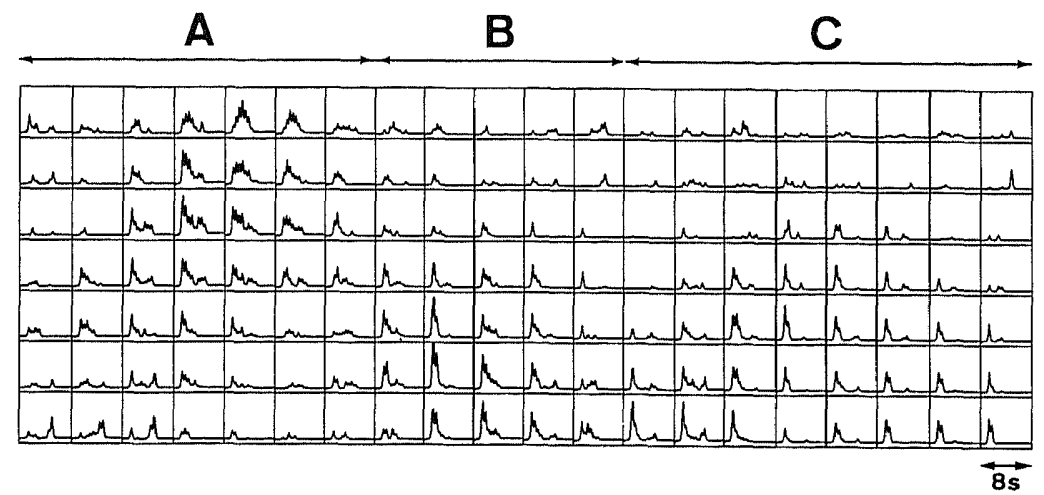

Fig. 15. Obtained moment rate function drawn from $1.0 \mathrm{~s}$ ahead of the arrival of the first time window at each grid point. The area shown is the same as the fault model shown in Figs. 12 and 13. 
H. Sekiguchi et al.

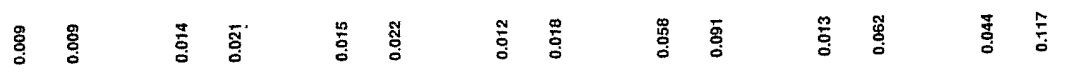

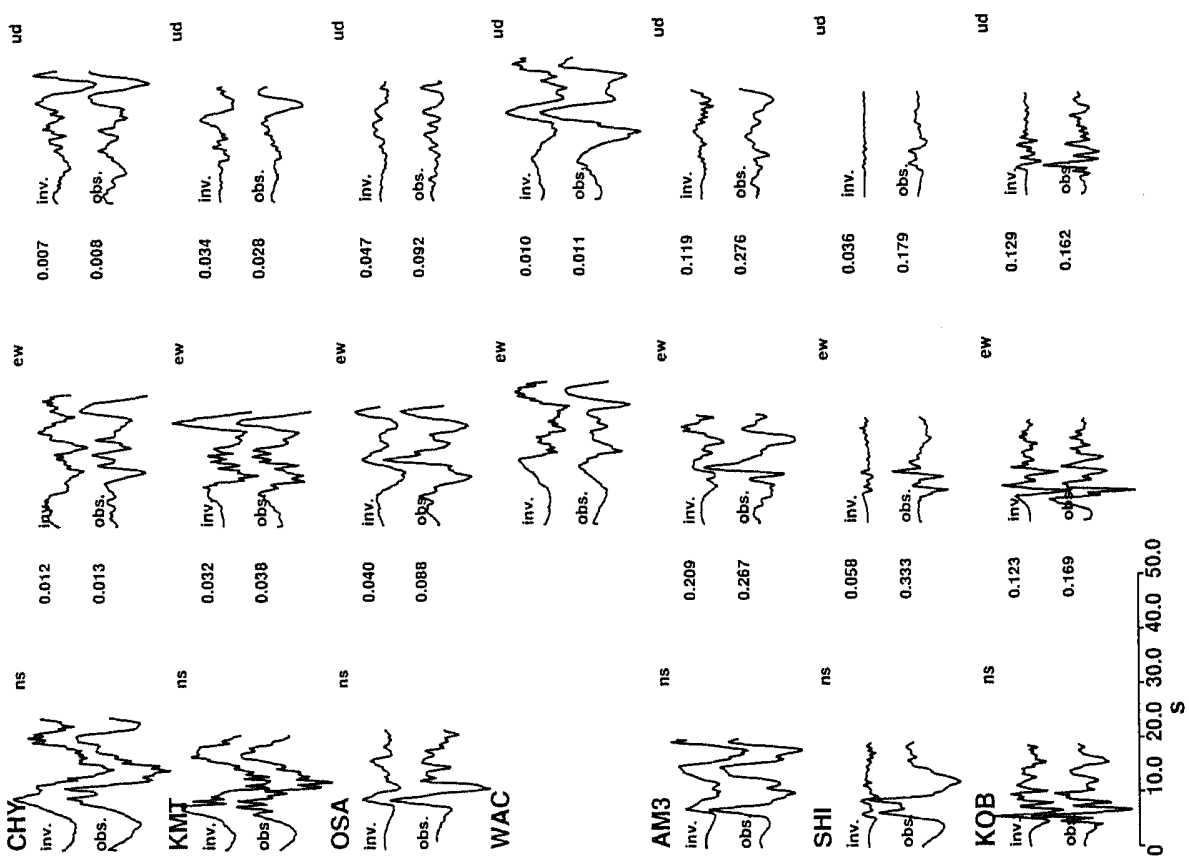

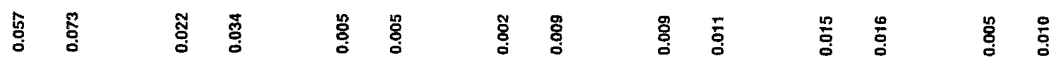

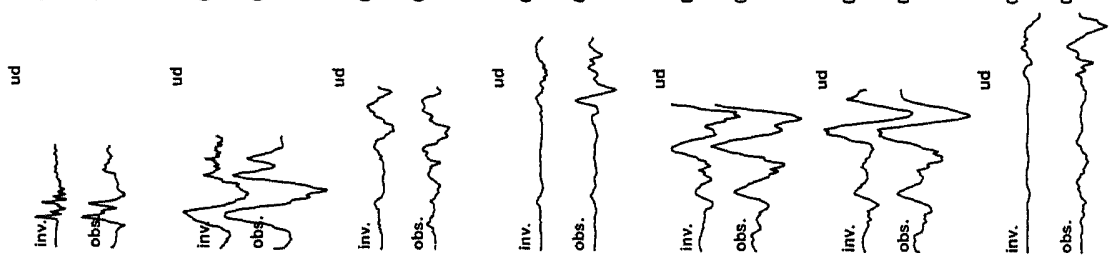

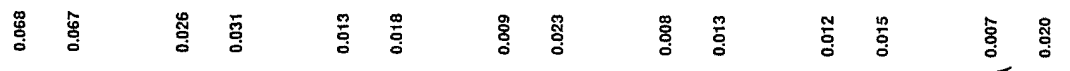

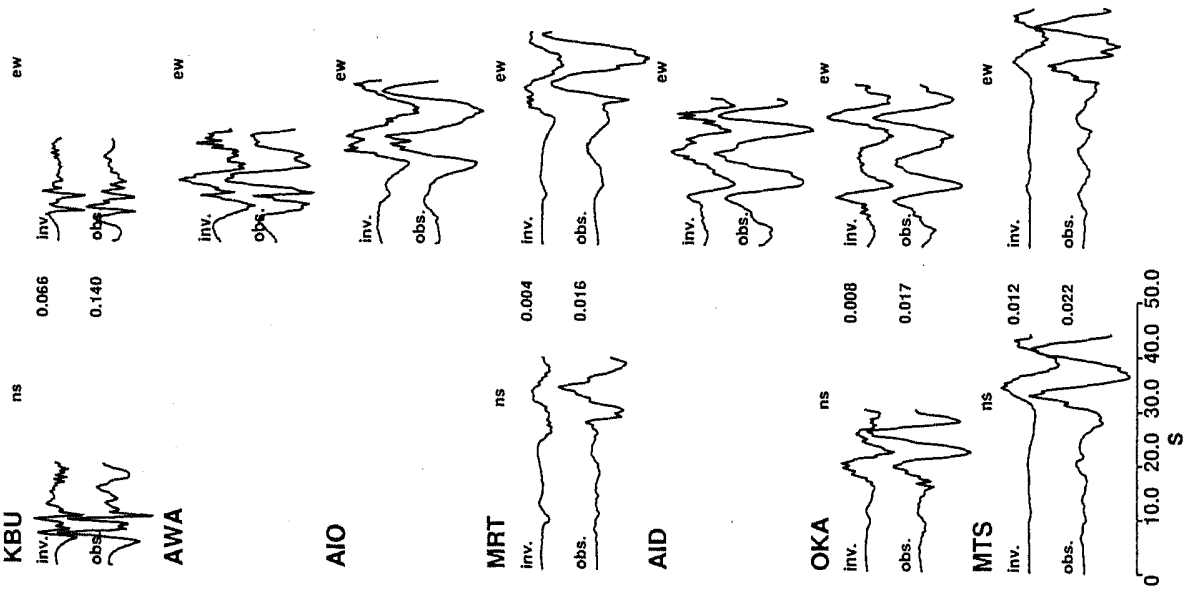




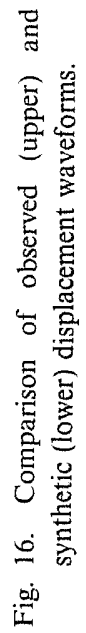

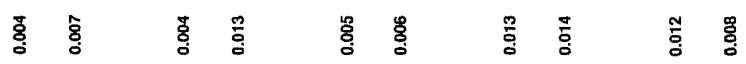
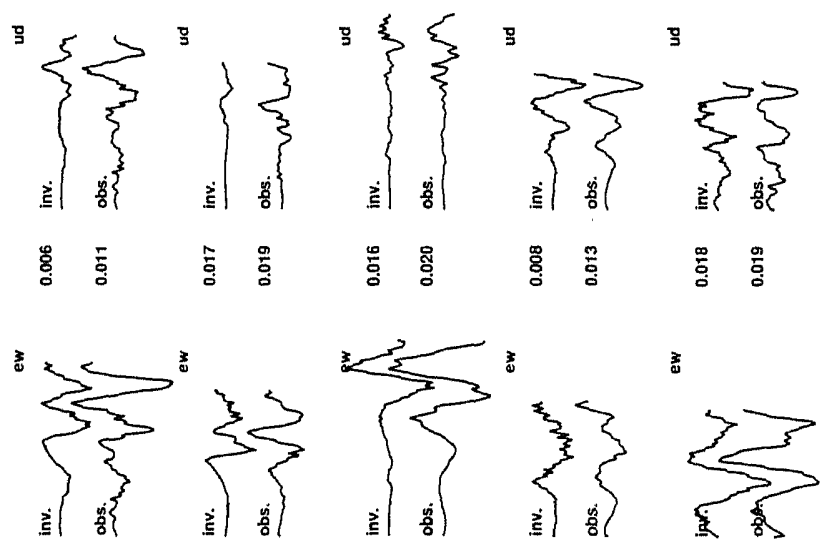

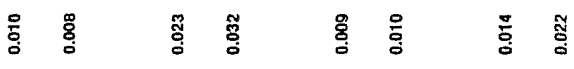

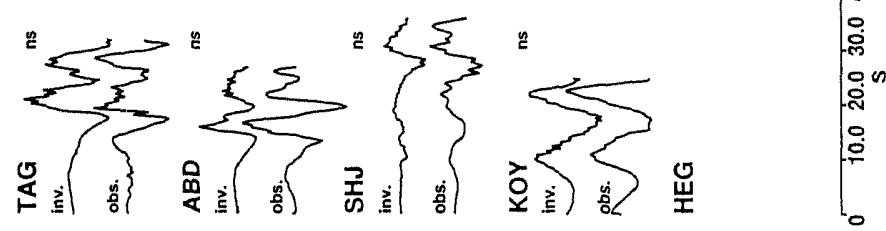


(a)

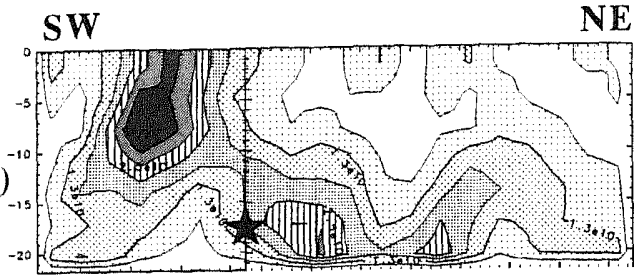

(b)

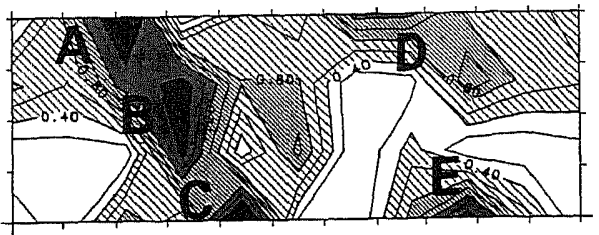

Fig. 17. (a) Total moment release density $(\mathrm{N} / \mathrm{m})$ distribution. The same figure as the lowest in Fig. 14. (b) The acceleration radiation intensities obtained from the envelope inversion of acceleration seismograms (Kakehi et al., 1996).

process are similar to those reported by Horikawa et al. (1996), Ide et al. (1996), Yoshida et al. (1996), and Wald (1996). The horizontal extent of the ruptured area was about $45 \mathrm{~km}$, reaching from $15 \mathrm{~km}$ southwest to $30 \mathrm{~km}$ northeast of the epicenter (Fig. 13). The horizontal component is dominant in the slip over the fault, except near the fault jump (between planes $\mathrm{A}$ and $\mathrm{B}$ ) at the Akashi strait and the northeastern edge of plane $C$. This may be caused by segmentation of the fault planes. As in the preliminary inversion, there are three separate regions with relatively large moment releases: 1) the first subevent around the rupture starting point, 2) the second subevent in the shallow (less than $10 \mathrm{~km}$ depth) part of the Nojima fault, and 3) the third deep (more than $10 \mathrm{~km}$ depth) subevent under Kobe City. At the large blank in the aftershock distribution, in the shallow part of fault "B" (Fig. 12), there is relatively small moment release. The largest slips $(1.55 \mathrm{~m})$ are in the second subevent area. The large slips in the shallowest grids in the second subevent area are consistent with the surface breaks along the Nojima fault. Their rake angles are also consistent with the southeast-side up trend along the Nojima fault (Nakata and Yomogida, 1995). The rise time near the surface in the second subevent area is long (about $4 \mathrm{~s}$, see Fig. 15), and may explain the relatively small disaster experienced on Awaji Island in spite of the large slip at small depth (notice that "rise time" here includes time for rupture propagation across a subarea related to the grid point). Examination of the contributions of the model fault to the synthesized waveforms in the Kobe area reveals that the most important source contributions were from the first and third subevents, but not from the second subevent. The moment release distribution in this frequency range $(0.1-1.0 \mathrm{~Hz})$ appears to have a pattern that is opposite to the high-frequency $(2.0-10.0 \mathrm{~Hz})$ wave radiating area estimated by Kakehi et al. (1996) (see Fig. 17). We conclude that the high-frequency wave radiation area is on the periphery of the low-frequency wave radiation area.

\section{Conclusion}

We estimated the source process of the Hyogoken Nanbu earthquake. From our investigation of the particle motion diagrams of observed seismograms in the near-source area in Kobe, we obtained constraints for the location of the fault in this area. These required us to put at least two faults to the northeast of the epicenter. On the basis of this result, we assumed a fault plane model and performed multi-time window linear waveform inversion. A right-lateral strike slip was dominant over the fault. There were three regions with relatively large moment releases; 1) around the rupture starting point, 2) in the shallow (less than $10 \mathrm{~km}$ depth) part of the Nojima fault, and 3) deep (about $10 \mathrm{~km}$ depth) under Kobe City. Even though the second subevent on the Awaji side had a large moment release, it did not generate pulsive waves because its rise time was long. The two remarkable pulses seen in seismograms of the Kobe area were from the first and third subevents.

We thank CEORKA; the JMA; Kansai Electric Power Co. Inc.; the Port and Harbor Research Institute; the Public Works Research Institute; the RCEP of the DPRI, Kyoto Univ.; the RRI, Kyoto Univ.; Osaka Gas; Kobe City; and David J. Wald for providing the strong ground motion data. We thank Takao Kagawa for providing and revising the records of MOT and KBU. We thank the RCEP of the DPRI, Kyoto University for allowing us to use their aftershock distribution figures. We thank Jean-Christophe Gariel for coding the programs for the discrete wavenumber method, Hiroshi Katao for aftershock focal mechanism data, Hiroo Nemoto for helping us to make figures, and David J. Wald, Arben Pitarka, and Haruo Horikawa for their helpful advice. We used the WIN 
program (Urabe and Tsukada, 1992) to show aftershock distribution). This work was partially supported by Grantsin-Aid for Scientific Research from the Ministry of Education, Science. Sports and Culture of Japan (Nos. 05302069 , 07300005).

\section{REFERENCES}

Aguirre, J, and K. Irikura, Preliminary analysis of non-linear site effects at port island vertical array station during the 1995 Hyogo-ken-Nambu earthquake, $J$. Nat. Disast. Sci., 16 (2), 49-58, 1995.

Bouchon, M., A simple method to calculate Green's function for elastic layered media, Bull. Seismol. Soc. Am., 71, 959-971, 1981.

Hartzell, S. H. and T. H. Heaton, Inversion of strong ground motion and teleseismic waveform data for the fault rupture history of the 1979 Imperial Valley, California earthquake, Bull. Seismol. Soc. Am., 73, 1553-1583, 1983.

Hashimoto, M., T. Sagiya, H. Tsuji, Y. Hatanaka, and T. Tada, Co-seismic displacements of the 1995 Hyogo-ken Nanbu earthquake, J. Phys. Earth, 44, 255-279, 1996.

Horikawa, H., K. Hirahara, Y. Umeda, M. Hashimoto, and F. Kusano, Simultaneous inversion of geodetic and strong motion data for the source process of the Hyogo-ken Nanbu, Japan, earthquake, J. Phys. Earth, 44, 455-471, 1996.

Ide, S. and M. Takeo, Source model of the Hyogo-ken Nanbu earthquake determined by near-field strongmotion records, J. Phys. Earth, 44, 649 653, 1996.

Kagawa, T., K. Irikura, and I. Yokoi, Restoring clipped records of the near field strong ground motion during the 1995 Hyogo-ken Nanbu, (Kobe), Japan earthquake, J. Nat. Disast. Sci., 18(1), 1996 (in press).

Kagawa, T., S. Sawada, Y. Iwasaki, and A. Nanjo, On the modelization of deep sedimentary structure beneath the Osaka plain, Abstr. Seismol. Soc. Jpn, 2, 112, 1993 (in Japanese).

Kakehi, Y., K. Irikura, and M. Hoshiba, Estimation of high-frequency wave radiation areas on the fault plane of the 1995 Hyogo-ken Nanbu earthquake by the envelope inversion of acceleration seismograms, $J$. Phys. Earth, 44, 505-517, 1996.

Kawase, H., Soil nonlinearity observed in the strong motion records during the Hyogo-ken Nambu Earthquake of 1995--Primarily on the simulation analysis of borehole records at Port Island, Proc. 4th Symp. on Dynamic Soil-Structure Interactions, Arch. Inst. Japan, 75-84, 1995 (in Japanese with English abstract).

Kennett, B. L. N. and N. J. Kerry, Seismic waves in a stratified half space, Geophys. J. R. astr. Soc. 57, 557-583. 1979.

Kikuchi, M., A shopping trolley seismograph, Nature, 377, 19, 1995.

Nakamura, Y., Report on Waveforms of the 1995 Hyogoken Nanbu Earthquake, JR Earthquake Information No. 23c, Railway Technical Research Institute, Tokyo, 50 pp., 1995 (in Japanese).

Nakata, T. and K. Yomogida, Surface fault characteristics of the 1995 Hyogoken-nambu Earthquake, J. Nat. Disast. Sci.. 16 (3), 1-9, 1995.

Pitarka A. and K. Irikura, Source complexity of the January 17, 1995 Hyogoken-nambu Earthquake determined by near-field strong motion modeling: preliminary results, J. Nat. Disast. Sci., 16 (2), 31-37, 1995.

Public Works Research Institute, Ministry of Construction, Strong-motion acceleration records from public works in Japan (No. 21), in Technical Note of Public Works Research Institute, Vol. 64, Public Works Research Institute, Ministry of Construction, Tsukuba, 1995.

Sekiguchi, H., K. Irikura, T. Iwata, Y. Kakehi, and M. Hoshiba, Determination of the location of faulting beneath Kobe during the 1995 Hyogo-ken Nanbu, Japan, earthquake from near-source particle motion, Geophys. Res. Lett., 23, 387--390, 1996.

Urabe, T. and S. Tsukada, Win-A workstation program for processing waveform data from microearthquake networks, Abstr. Seismol. Soc. Jpn., 2, 331, 1992 (in Japanese).

Wald D. J., Slip history of the 1995 Kobe, Japan, earthquake determined from strong motion, teleseismic, and geodetic data, J. Phys. Earth, 44, 489-503, 1996.

Yoshida, S., K. Koketsu, B. Shibazaki, T. Sagiya, and Y. Yoshida, Joint inversion of near- and far-field waveforms and geodetic data for the rupture process of the 1995 Kobe earthquake, $J$. Phys. Earth, 44, 437-454, 1996. 